\title{
'Effectiveness of Breathing Exercises in Improving the Breathing Pattern of Asthmatic Children in a Selected Hospital'
}

\author{
Mr. Jibin V. Varkey ${ }^{1}$, Mrs. K. Yeshoda ${ }^{2}$ \\ Assistant Professor, MIMS College of Nursing ${ }^{l}$ \\ Principal \& Head of the Department of Child HealthNursing, College of Nursing, GopalaGowdaShanthaveri \\ Memorial Hospital Trust ${ }^{2}$
}

\begin{abstract}
Asthma is a common chronic inflammatory disease of the airways characterized by variable and recurring symptoms, reversible airflow obstruction, and bronchospasms. Asthma statistics showed that 300 million people worldwide suffer from asthma, with 250,000 annual deaths attributed to the disease. Researcher felt that breathing exercises are more effective to improve the quality of life of asthmatic children. The objectives were; to assess the breathing pattern of asthmatic children before introducing breathing exercise in both experimental and control group, to teach techniques of breathing exercises to asthmatic children in experimental group, to assess the breathing pattern of asthmatic children in both experimental and control group for 5 days, to assess the effectiveness of breathing exercises in improving the breathing pattern of asthmatic children, to compare the rate of reduction in respiratory distress between experimental and control group of asthmatic children and to find the association between the breathing pattern of asthmatic children and selected demographic variables. The study was carried out in Cheluvamba Government Hospital for Women and Children, Mysore. Data were obtained from 60 children admitted in Hospital. Three point scales for assessing respiratory pattern of asthmatic children was used for the data collection. Purposive sampling technique was used. The research design of study was time series non-equalent control group design.The results of study revealed that total rate of reduction of respiratory distress in experimental and control group was 281 and 50 respectively where as standard deviation of experimental and control group was 4.8 and 5.1 respectively and reduction of respiratory distress after intervention with t- test was 5.4 which were higher than the table value $\left(t_{58}=1.96, p>0.05\right)$. Hence the research hypothesis $\left(H_{1}\right)$ was accepted suggesting that breathing exercises was more effective in improving the breathing pattern of asthmatic children. The chi- square test revealed that there was a significant association between home environment 41.79 and breathing pattern of children, where as there was no significant association between age and waste disposal $(\chi 2=2.28,0.54$ respectively) and breathing pattern of asthmatic children.
\end{abstract}

Key Words: Breathing exercises; Asthma

\section{Introduction}

"When you inhale, you are taking the strength from God. When you exhale, it represents the service you are giving to the world"

-B.K.S. Iyengar.

Asthma is a common chronic inflammatory disease of the airways characterized by variable and recurring symptoms, reversible airflow obstruction, and bronchospasms. Asthma statistics showed that 300 million people worldwide suffer from asthma, with 250,000 annual deaths attributed to the disease. ${ }^{1}$

Asthma the most common chronic disease of childhood, is the primary cause of school absence, and is responsible for a major proportion of Pediatric admission to emergency departments and hospitals. The onset of asthma may occur at any age, and $80 \%$ to $90 \%$ of children have their first symptoms before 4 or 5 years of age. Boys are affected more frequently than girls until adolescence, when the trend reverses. The severity of disease varies among children and is not influenced by sex. ${ }^{2}$

Breathing exercises are considered part of complementary and alternative medical treatments. There are many different kinds of breathing exercises ranging from ancient techniques based on yoga to modern biofeedback training systems. On the face of it, claims of improvement may seem to have a basis, because asthma is a disease of the lungs and so might respond to training in breathing. ${ }^{3}$ Researcher felt that breathing exercises are more effective to improve the quality of life of asthmatic children.

\section{Statement of the problem}

"A Study To Assess The Effectiveness Of Breathing Exercises In Improving The Breathing Pattern Of Asthmatic Children Admitted In Cheluvamba Government Hospital For Women And Children, Mysore" 


\section{The objectives of the study were to:}

- Assess the breathing pattern of asthmatic children before breathing exercises in both experimental and control group.

- Teach techniques of breathing exercises to asthmatic children in experimental group.

- Assess the breathing pattern of asthmatic children in both experimental and control group for 5 days.

- Assess the effectiveness of breathing exercises in improving the breathing pattern of asthmatic children.

- Compare the rate of reduction in respiratory distress between experimental and control group of asthmatic children.

- Find the association between the breathing pattern of asthmatic children and selected demographic variables. (Age, home environment, waste disposal)

- Setting of the study:

\section{Method}

The present study was undertaken in Cheluvamba Government Hospital for Women and Children, Mysore due to the geographical proximity, feasibility of the study and availability of the samples.

\section{- Data collection instruments}

Demographic proforma and a three point scales for assessing respiratory pattern of asthmatic children were used for the data collection.

\section{- Sample and sampling technique}

In this studythe sample size will be 60 children, who are diagnosed to have asthma admitted inCheluvamba Government Hospital for Women and Children, Mysore. Sampling technique adopted for the selection of sample is purposive sampling

\section{- $\quad$ Research design}

The research design of study was time series non- equalent control group design

\section{Results}

The study revealed that total rate of reduction of respiratory distress in experimental and control group was 281 and 50 respectively where as standard deviation of experimental and control group was 4.8 and 5.1 respectively and reduction of respiratory distress after intervention with t- test was 5.4 which were higher than the table value $\left(\mathrm{t}_{58}=1.96, \mathrm{p}>0.05\right)$. Hence the research hypothesis $\left(\mathrm{H}_{1}\right)$ was accepted suggesting that breathing exercises was more effective in improving the breathing pattern of asthmatic children. The chi- square test revealed that there was a significant association between home environment 41.79 and breathing pattern of children, whereas there was no significant association between age and waste disposal $(\chi 2=2.28,0.54$ respectively) and breathing pattern of asthmatic children.

Table 1: Classification of respondents by frequency of asthma attack, home environment, fuel used, associated

\begin{tabular}{|c|c|c|c|}
\hline Socio Demographic data & Category & \multicolumn{2}{|c|}{ Respondent } \\
\hline \multirow{2}{*}{$\begin{array}{l}\text { Frequency of asthma attack to the } \\
\text { child }\end{array}$} & Continuous & 32 & $53.33 \%$ \\
\hline & Recurrent & - & - \\
\hline \multirow[b]{2}{*}{ Home environment } & Overcrowding & 24 & $40 \%$ \\
\hline & Smoking & 31 & $51.7 \%$ \\
\hline \multirow{3}{*}{ Fuel used for cooking } & Fire wood & 30 & $50 \%$ \\
\hline & Gas & 18 & $30 \%$ \\
\hline & Electricity & 12 & $20 \%$ \\
\hline \multirow{3}{*}{ Associated diseases of asthma } & COPD & 43 & $71.7 \%$ \\
\hline & Hyper reactive airway diseases & 6 & $10 \%$ \\
\hline & Respiratory diseases & 11 & $18.33 \%$ \\
\hline
\end{tabular}




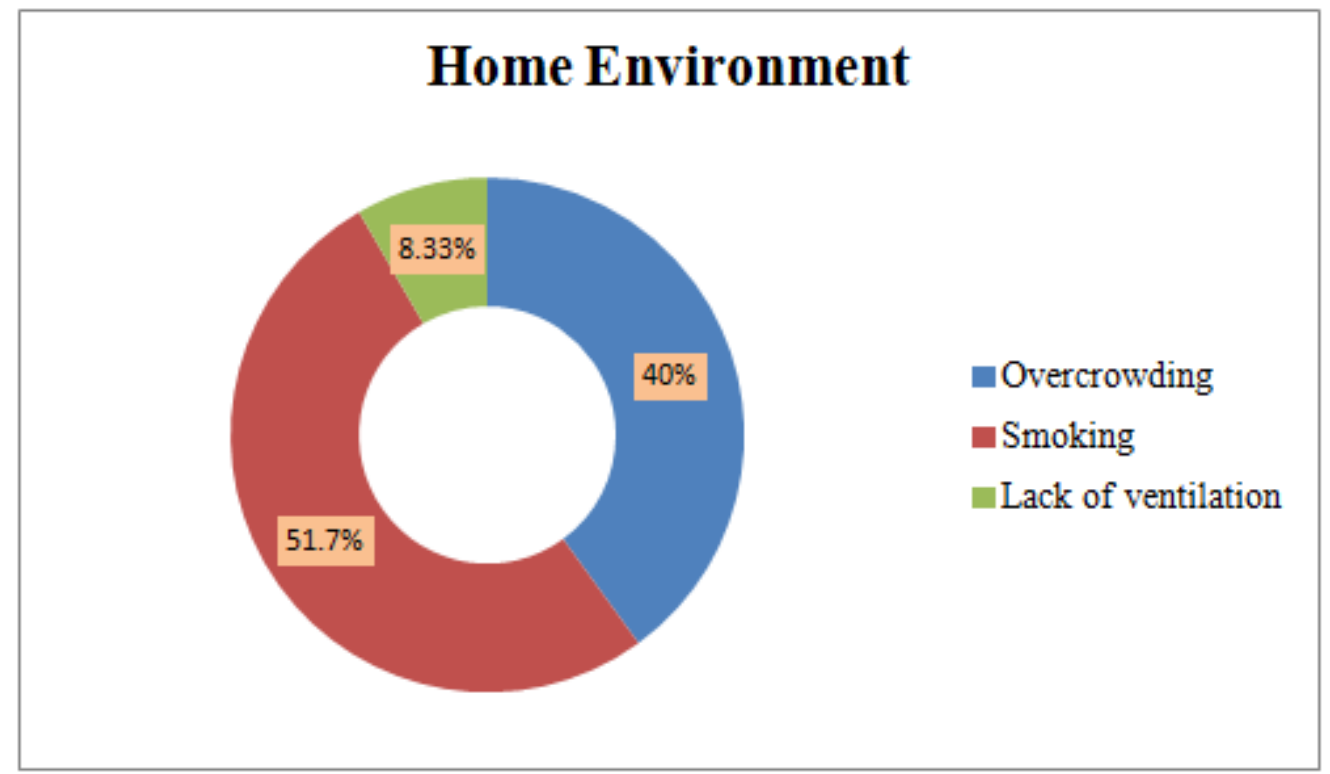

Figure 1: Distribution of respondents by Home environment

Figure 1 reveals that home environment of the children majority 31 (51.7\%) were in smoking area, 24 (40\%) were Overcrowding, 5 (8.33\%) were from Lack of ventilation area.

Table 2: Findings related to the effectiveness of breathing exercises in improving the breathing pattern $n=60$

\begin{tabular}{|c|c|c|c|c|}
\hline Group & $\begin{array}{c}\text { Total rate of reduction of } \\
\text { respiratory distress }\end{array}$ & Mean & SD & \multirow{2}{*}{ t- Test } \\
\hline Experimental group & 281 & 9.37 & 4.8 & \multirow{2}{*}{5.4} \\
\hline Control group & 50 & 1.67 & 5.1 & \\
\hline Difference & 231 & 7.7 & -0.3 & \\
\hline
\end{tabular}

Table 2 reveals that the total rate of reduction of respiratory distress in experimental and control group was 281 and 50 respectively where as standarddeviation of experimental and control group is 4.8 and 5.1 respectively and reduction of respiratory distress after intervention is 5.4 i.e. $\mathrm{t}$ - test value is higher than the table value $\left(\mathrm{t}_{58}=1.96, \mathrm{p}>0.05\right)$. Hence the research hypothesis $\left(\mathrm{H}_{1}\right)$ is accepted suggesting that breathing exercises is effective in improving the breathing pattern of asthmatic children.

Table 3:Association between the selected socio demographic variables and breathing pattern of asthmatic children $\mathrm{n}=60$

\begin{tabular}{|c|c|c|c|c|c|c|}
\hline \multicolumn{2}{|c|}{ Variables } & Moderate & Severe & df & table value & $x^{2}$ \\
\hline \multirow[t]{2}{*}{ Age of the child } & $06-08$ & 9 & 24 & \multirow[t]{2}{*}{1} & \multirow[t]{2}{*}{3.841} & \multirow[t]{2}{*}{$2.28 \mathrm{NS}$} \\
\hline & $08-10$ & 12 & 15 & & & \\
\hline \multirow[t]{3}{*}{ Waste Disposal } & Burial & 11 & 21 & \multirow[t]{3}{*}{2} & \multirow[t]{3}{*}{5.99} & \multirow[t]{3}{*}{$0.54 \mathrm{NS}$} \\
\hline & Dumping & 10 & 17 & & & \\
\hline & Incineration & 0 & 1 & & & \\
\hline Home environment & Over crowding & 6 & 18 & 2 & 5.99 & $41.79 *$ \\
\hline \multirow[t]{3}{*}{ Home environment } & Over crowding & 6 & 18 & \multirow[t]{3}{*}{2} & \multirow[t]{3}{*}{5.99} & \multirow[t]{3}{*}{$41.79^{*}$} \\
\hline & Smoking & 14 & 17 & & & \\
\hline & Lack of ventilation & 1 & 4 & & & \\
\hline
\end{tabular}

Table 3reveals that chi- square value of Home environment 41.79 which is greater than the table value was significant. Variables like age and waste disposal chi- square value was $2.28,0.54$ respectively were not significant. Hence the research hypothesis $\left(\mathrm{H}_{2}\right)$ is rejected in relation to age and method of waste disposal.

\section{Interpretation and Conclusion}

The study revealed that breathing exercises was effective in improving the breathing pattern of asthmatic children thus it can be used as an effective techniques in child care settings. 


\section{References:}

[1]. Asthma Statistics American academy of allergy asthma and immunology, World Health Organization, Global surveillance, prevention and control of chronic respiratory diseases, a comprehensive approach. [Online]. 1996-2009 [cited 2009 Sep 20]; Available From: URL:http://www.aaaai.org/media/statistics/asthma-statistics.asp.

[2]. Donna LW. Whaley $\&$ Wong's nursing care of infants and children. $6^{\text {th }}$ ed. St. Louis: Mosby; 1999. p.1499.

[3]. Gaining asthma relief through breathing exercises. Ads by goggles [Online]. 2007 [cited 2009 Sep 3]; Available From: URL:http://www.whatisasthma.net/breathing-exercises.php

\section{Key Words}

Breathing exercises; Asthma 